This item was submitted to Loughborough's Research Repository by the author.

Items in Figshare are protected by copyright, with all rights reserved, unless otherwise indicated.

\title{
Fibres from blends of epoxidized natural rubber and polylactic acid by the electrospinning process: compatibilization and surface texture
}

PLEASE CITE THE PUBLISHED VERSION

http://dx.doi.org/10.1016/j.eurpolymj.2016.12.033

\section{PUBLISHER}

(C) Elsevier

VERSION

AM (Accepted Manuscript)

\section{PUBLISHER STATEMENT}

This work is made available according to the conditions of the Creative Commons Attribution-NonCommercialNoDerivatives 4.0 International (CC BY-NC-ND 4.0) licence. Full details of this licence are available at: https://creativecommons.org/licenses/by-nc-nd/4.0/

\section{LICENCE}

CC BY-NC-ND 4.0

\section{REPOSITORY RECORD}

Mascia, Leno, Ruixue Su, Jane Clarke, Yu Lou, and Elisa Mele. 2017. "Fibres from Blends of Epoxidized Natural Rubber and Polylactic Acid by the Electrospinning Process: Compatibilization and Surface Texture". figshare. https://hdl.handle.net/2134/23976. 


\title{
Fibres from blends of epoxidized natural rubber and polylactic acid by the electrospinning process: Compatibilization and surface texture.
}

\author{
Leno Mascia*, Ruixue Su, Jane Clark, Yu Lou, Elisa Mele \\ Department of Materials, Loughborough University, Loughborough LE11 3TU, UK \\ *Corresponding author: L.Mascia@lboro.ac.uk
}

\begin{abstract}
Fibres were electrospun from blends of an epoxidized natural rubber (ENR) with a minor amount of a crystalline grade of polylactic acid (PLA), using a graft copolymer compatibilizer (ENR-g-JM) produced by reaction processing of a mixture of PLA and monoamine terminated polypropylene glycol (Jeffamine M600). The incorporation of PLA into the elastomer spinning solution in the form of a blend was necessary to obtain the required solution properties and to establish the appropriate operational conditions for the successful electrospinning of fibres. The addition of a small quantity of compatibilizer to the ENR/PLA blend reduced the severity of surface roughness of the fibres. Moreover, the use of monoamine terminated polypropylene glycol alone, as a plasticizer, was also found to exert a control on the development of surface texture during electrospinning. The rate of solvent induced crystallization in the swollen fibres jet was identified as the factor determining the surface topography.
\end{abstract}

Keywords: Blend; Compatibilization; Epoxidized natural rubber; Electrospinning; Jeffamine, Polylactic acid 


\section{Introduction}

Electrospinning is an attractive method for the manufacture of polymer based fibres with a wide range of diameters varying from a few microns down about $10 \mathrm{~nm}$ by controlling the properties of polymer solutions or melts and the processing parameters [1, 2]. Furthermore, different fibre assemblies can be obtained through changes in the electrical field and through the use static and dynamic collection systems [3]. The use of rotating collectors makes it possible to introduce molecular orientation as a means of increasing the tenacity (tensile strength) of the fibres [4,5]. Elastomeric fibres also have been produced by electrospinning [6,7] and the successful use of in-line ultraviolet (UV) curing has been claimed by some authors [8,9]. Electrospun fibres are invariably collected as mats for use in issue engineering, filtration and sensors, where a high level of porosity and a large surface to volume ratio are required [10-13].

Although the development of biodegradable fibres by electrospinning has attracted the attention of many researchers in recent years only a few studies have been reported on elasticated fibres from renewable resources. Hao et al. [14], for instance, have produced smooth electrospun fibres with diameters of 5-8 $\mu$ from chloroform solutions of synthetic cis-1,4-polyisoprene using a roll take-off unit. The fibres produced displayed a characteristic bamboo-like geometry with regular periodic nodes at $20-60 \mu \mathrm{m}$ distance along the length. Manzine Costa et al. [15] have produced fibres from polycaprolactone solution in chloroform mixed with different amounts of a natural rubber (NR) solution in toluene. Cacciotti et al. [16], on the other hand, have produced fibres from both NR and NR containing suspensions of graphene nanoplatelets in the rubber solution.

No work has been reported so far, to the best of our knowledge, on the use of epoxidized natural rubber (ENR) either as a single component system or in blends with minor amounts of an auxiliary polymer. In a very recent report Cosme et al [17] have shown that PLA fibres can be successfully produced with the addition of amounts of ENR up to $50 \%$, which was found to increase slightly the degree of crystallinity. No attempt was made, however, to control or manipulate the distribution of the two constituent domains within the fibres through the use a third component as a compatibilizing agent.

ENR is obtained by introducing epoxy functionalities into NR by controlled oxidation reactions $[18,19]$. The original aim of this polymer modification was to introduce polar 
groups along the chains of NR as a way of improving certain physicochemical properties, such as resistance to oil and solvents. The described chemical modification is particularly valuable also for the production of biodegradable systems, insofar as it is expected to enhance the degradation characteristics of NR by microorganisms in products where catalytic proteins are removed from the original latex $[20,21]$. Blends of ENR with biodegradable polymers would provide a viable route for the manufacture of products with enhanced biodegradability [22]. In this work polylactic acid (PLA) was chosen as the minor component of the ENR fibres for its established position as a biodegradable polymer, as well as for its availability in a crystalline form.

A major aim of this work is to explore the possibility of tailoring the morphology of the blend by the addition of a compatibilizer produced by reacting ENR with small amounts of a monoamine terminated propylene glycol oligomer, according to the scheme shown in Figure 1, using a laboratory size melt mixing device. It should be noted that the work addresses for the first time the use of a compatibilizing agent, as a permanent third component, in the formulation of blends for the production of fibres by the electrospinning process.

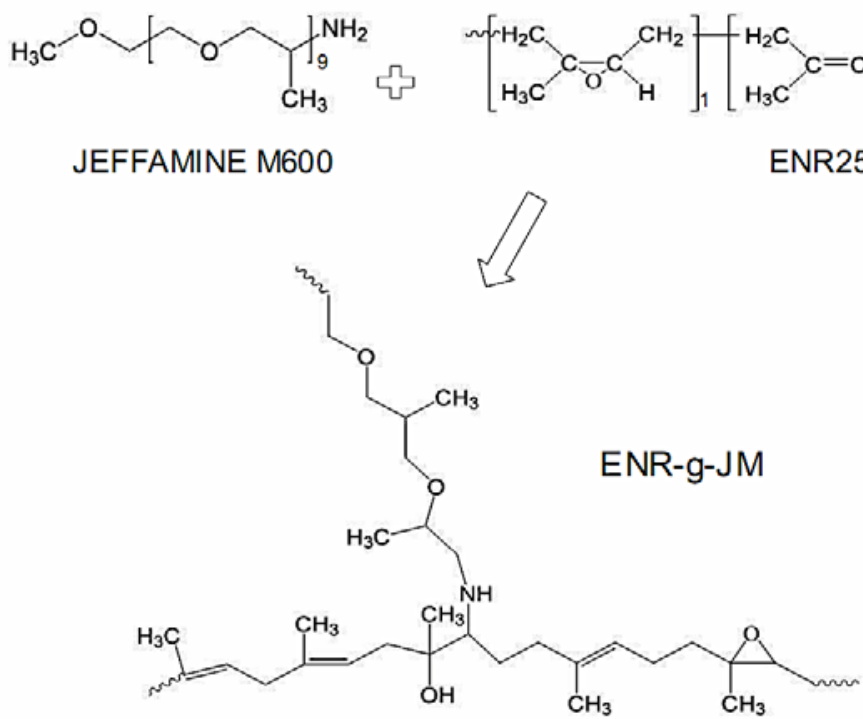

Figure 1: Reaction scheme for the production of a graft copolymer of epoxidized natural rubber with monoamine terminated propylene glycol oligomer (ENR-g-JM). 
A propylene glycol oligomer (PPG) derivative was chosen for this work on account of the reported thermodynamic miscibility of polypropylene glycol with PLA, as well as for its low toxicity rating, which makes it more suitable than the corresponding polyethylene glycol derivatives for biotechnology applications [21]. The rationale is founded on the hypothesis that the monoamine derivative of PPG is not conducive to produce cross-links through further reactions of the secondary amine resulting from the first step of the reaction shown in Figure 1 , on account of the steric effects imposed by the methyl groups adjacent to both the epoxy group in the ENR, which may also be impeded by spatial restrictions inherent to the molecular dimension of the reactants.

\section{Experimental}

\section{Materials}

a) Jeffamine M600: o-(2-Aminoropyl)-o'-(2-methoxyethyl) polypropylene glycol with an average Mn of 600 was purchased from Sigma Aldrich. It is a liquid with a melting point of $-40{ }^{\circ} \mathrm{C}$ and a flash point of $129^{\circ} \mathrm{C}$.

b) The auxiliary polymer component was a crystalline grade of PLA, known under the trade name Ingeo Biopolymer 6202D, which consists of $98 \%$ L-lactide units and has a weight average molecular weight of $140 \mathrm{kDa}$.

c) Epoxidized natural rubber: Epoxyprene 25 (ENR25), with a $25 \mathrm{~mol} \%$ nominal level of epoxidation, manufactured by Muang Mai Guthrie Public Limited Company of Thailand, was obtained from Tun Abdul Razak Research Centre. The technological molecular weight expressed as Mooney viscosity is given as $\mathrm{M}_{\mathrm{L}, 1+4\left(100{ }^{\circ} \mathrm{C}\right)}=110$, equivalent to an $\overline{\bar{M}} n$ value in the region of $80 \mathrm{kDa}$. The glass transition temperature (Tg) is approximately $-45{ }^{\circ} \mathrm{C}$.

d) Chloroform, used as solvent for the individual polymers and the blends, was purchased from Sigma Aldrich. 


\section{Preparation of feedstock materials for electrospinning}

Mixtures of different compositions were produced using a Haake mixer according to the details shown in Table 1. Approximately 50 grams of raw material was mixed in each run, using Banbury rotors R600 at $80 \mathrm{rev} / \mathrm{min}$ rotation speed. In all cases PLA was pre-dried at 60 ${ }^{\circ} \mathrm{C}$ for 24 hours.

Table 1 Compositions and mixing conditions of mixtures (JM stands for Jeffamine M600)

\begin{tabular}{|l|l|l|l|l|l|l|}
\hline Code & $\begin{array}{l}\text { ENR 25 } \\
(\mathrm{w} \%)\end{array}$ & $\begin{array}{l}\text { PLA } \\
(\mathrm{w} \%)\end{array}$ & $\begin{array}{l}\text { Jeffamine } \\
\mathbf{M 6 0 0}(\mathrm{w} \%)\end{array}$ & $\begin{array}{l}\text { ERN-g-JM } \\
(\mathrm{w} \%)\end{array}$ & $\begin{array}{l}\text { Temperature } \\
\left({ }^{\circ} \mathrm{C}\right)\end{array}$ & $\begin{array}{l}\text { Time } \\
(\text { minutes })\end{array}$ \\
\hline ENR & 100 & & & & 100 & 20 \\
\hline ENR-g-JM & 85 & & 15 & & 100 & 20,40 \\
\hline Binary Blend B & 70 & 30 & & & 165 & 15 \\
\hline Compatibilized Blend E & 40 & 30 & & 30 & 165 & 12 \\
\hline
\end{tabular}

From the stoichiometry of the reaction in Figure 1 it is estimated that the amount of Jeffamine M600 grafted to ENR25 in the ENR-g-JM compatibilizer would produce branches attached to ENR polymer backbone consisting of 30-atom segments at a rate of approximately 1 for every 12 repeating units along chains. This structure derives from an estimated molar ratio Jeffamine M 600 : ENR 25 = $1: 12$, based on the molecular weight of the repeating unit for ENR25 equal to $277 \mathrm{Da}$ and for Jeffamine M600 equal to $600 \mathrm{Da}$. In addition to the formulations in Table 1 several ad hoc auxiliary mixes were also produced as reference data to aid the discussion.

The mixing time and temperature were set according to the extent of reaction expected and to ensure an adequate degree of mixing. The torque exerted by the rotors during mixing was recorded to monitor the changes in melt viscosity.

\section{Electrospinning runs}

Solutions in chloroform at 6,8 and $10 \mathrm{w} / \mathrm{v} \%$ concentration were used to determine the experimental conditions required to produce fibres by electrospinning with an apparatus manufactured by Linari Engineering. The syringes have a $1 \mathrm{~mL}$ capacity with a $21 \mathrm{G}$ needle 
$80 \mathrm{~mm}$ long and a bore diameter of $0.6 \mathrm{~mm}$. An additional composition, coded Blend B+JM, was also electrospun into fibres. This was obtained by adding Jeffamine to the binary Blend B solution in amounts equivalent to those used in the production of the compatibilized Blend E system.

The applied voltage, flow rate through the syringes and distance from the earthed collector were systematically changed and fibres were produced under suitable conditions, which varied according to composition of the feed stock mixture.

\section{Characterization techniques}

Fourier transform infrared (FTIR) analysis was used to obtain a quantitative estimate of the epoxy groups in the ENR component at $870 \mathrm{~cm}^{-1}$ and the carbonyl groups in the PLA part of the mixture at $1750 \mathrm{~cm}^{-1}$, using a Shimadzu FTIR-8400S instrument. The chloroform solutions used for the production of the fibres was spread on a $\mathrm{KBr}$ disc and dried under infrared lamp. The range of scan used is 600 to $4000 \mathrm{~cm}^{-1}$ with 64 scans for each sample with a resolution of $4.0 \mathrm{~cm}^{-1}$. The spectra obtained were analysed by comparing them with the equivalent ENR/PLA solution mixture prepared directly from the constituents. The height of the peaks was used to estimate the extent of conversion of the epoxy groups during processing.

Optical microscopy examinations were made to determine the best electrospinning conditions by visual inspection.

The fibres made from binary Blend B and compatibilized Blend E were analysed by differential scanning calorimetry (DSC) using a TA Instrument series Q200 Thermal Analyser, alongside control samples of the raw materials used as $8 \%$ solutions. The fibres were allowed to stand at room temperature for at least one week before the DSC runs were performed. Samples in the range $5-10 \mathrm{mg}$ were heated from $20^{\circ} \mathrm{C}$ to $200^{\circ} \mathrm{C}$ at a heating rate of $10^{\circ} \mathrm{C} / \mathrm{min}$ under nitrogen flow of $50 \mathrm{ml} / \mathrm{min}$. The Tg of the rubber phase was obtained from the thermograms in the temperature range $-70^{\circ} \mathrm{C}$ to $-10^{\circ} \mathrm{C}$ using scans at $5{ }^{\circ} \mathrm{C} / \mathrm{min}$ in nitrogen atmosphere. 
Scanning Electron Microscope (SEM) was used to examine the morphology of the fibres produced. In the case of cast films a 1 millimetre wide strip was immersed in liquid nitrogen and broken into two parts using forceps in order to examine the cross-section. The fibres would not break after immersions in liquid nitrogen and were, therefore, cut into small pieces and directly pasted onto the carbon tab and then pasted on aluminium stubs. After applying a silver conductive coating the specimens were placed into the vacuum chamber of the SEM apparatus and scanned to produce image.

\section{Results and Discussion}

\section{Torque evolution during mixing}

The torque exerted in the mixing operations, recorded by the instrumentation of the Haake mixer, was used to examine the changes during mixing. In Figure 2 are compared the torque traces for the processing of the raw ENR and the mix with the Jeffamine for the production of the compatibilizer ENR-g-JM and also for the binary Blend B alongside that obtained for the production of the compatibilized Blend E.

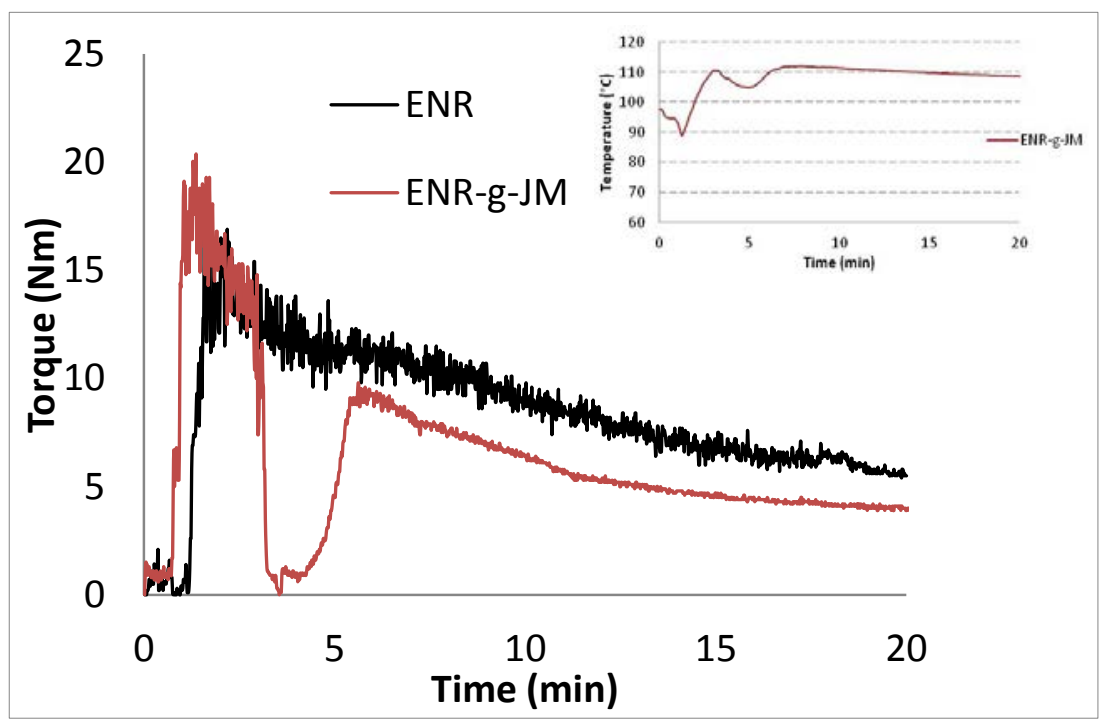




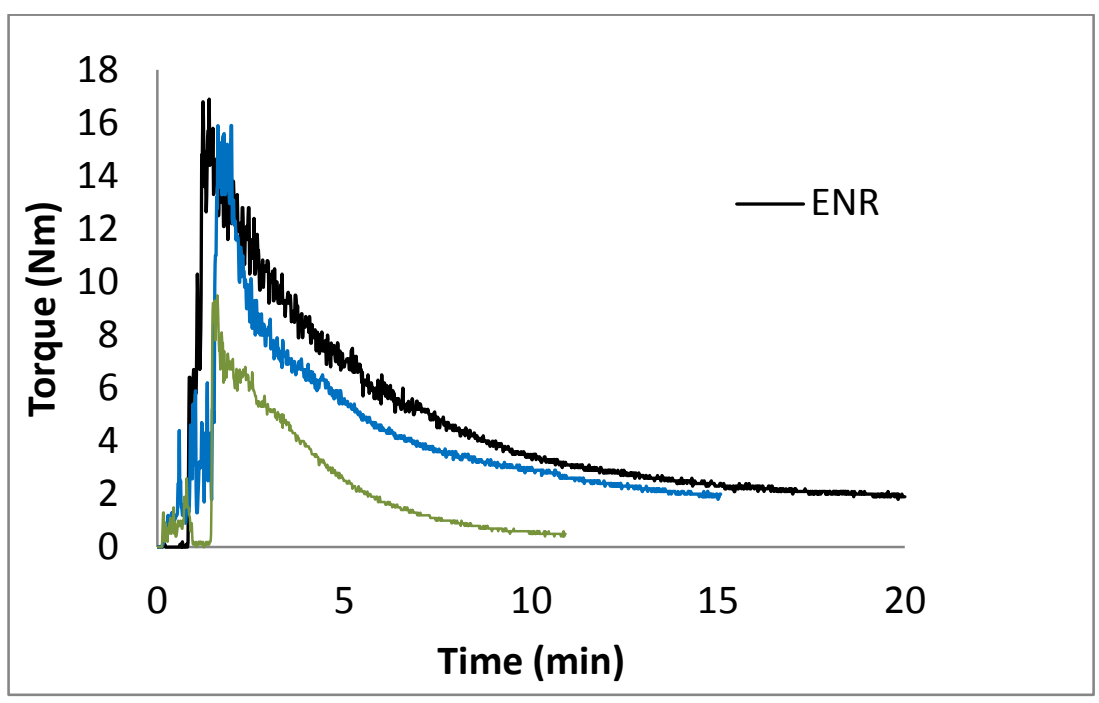

Figure 2. Torque traces recorded on the Haake mixer in various runs the production of the mixes and auxiliary materials. Top: ENR and compatibilizer ENR-g-JM mixed at $100^{\circ} \mathrm{C}$, with temperature variation as inset (Jeffamine was added at 3 min processing time). Bottom: ENR, binary blend B and compatibilized blend E mixed at $165^{\circ} \mathrm{C}$.

The traces in Figure 2 show that in all cases there is a gradual reduction in the torque due to degradation of either or both ENR and PLA components, as already reported elsewhere [2226]. The traces in Figure 2 (Top) shows that the addition of Jeffamine causes an immediate drop in the torque to an extremely low level due to the lubrication effect of the low viscosity component, followed by a gradual increase to steady-state values, which are lower than those recorded for the ENR control. This is accompanied by a concomitant trough in the temperature trace (see inset) due to the cooling effect brought about by the sudden addition of the cold liquid reactant. Both events indicate that Jeffamine M600 is miscible with ENR25 and that it exerts the expected plasticization effect on the melt viscosity. The reduction in the slope of the traces from about 11 minutes mixing time, on the other hand, could be interpreted as a manifestation of the onset of the grafting reaction illustrated in Figure 1. The large reduction in the mixing torque experienced for the mixing runs at $165{ }^{\circ} \mathrm{C}$ is clearly evidenced in the traces in Figure 2 (Bottom) from which is also evident a decrease in the mixing torque resulting from the addition of PLA to ENR in the binary Blend B. An additional large drop in the torque is observed in the presence of the compatibilizer ENR-g$\mathrm{JM}$ for the production of the compatibilized Blend E. Since the quantity of Jeffamine 
component is only $4.5 \%$ (see Table 1 ) the very large reduction in the viscosity of the mix, which becomes increasingly more prominent at longer mixing times, has to be attributed to degradation by chain scission, possibly in both components. In earlier work we have reported the catalytic effect of moieties with carboxylic acid groups on the ring opening of epoxy groups as precursors for chain scission reactions [26].

\section{FTIR spectroscopy}

The FTIR spectra in Figure 3 clearly identify the absorption peaks for the two main relevant groups for the ENR/PLA blends used for the production of the fibres, respectively $\sim 870 \mathrm{~cm}^{-1}$ for the epoxy groups [26] and at $\sim 1750 \mathrm{~cm}^{-1}$ for the $\mathrm{C}=\mathrm{O}$ groups in the PLA. In view of the merging of the absorption band for the epoxy at $\sim 870 \mathrm{~cm}^{-1}$ with that at $\sim 837 \mathrm{~cm}^{-1}$ for the C-C bonds, the height of peaks from the base line instead of the area was used to determine the degree of conversion of epoxy groups. The relevant data are summarized in Table 2.

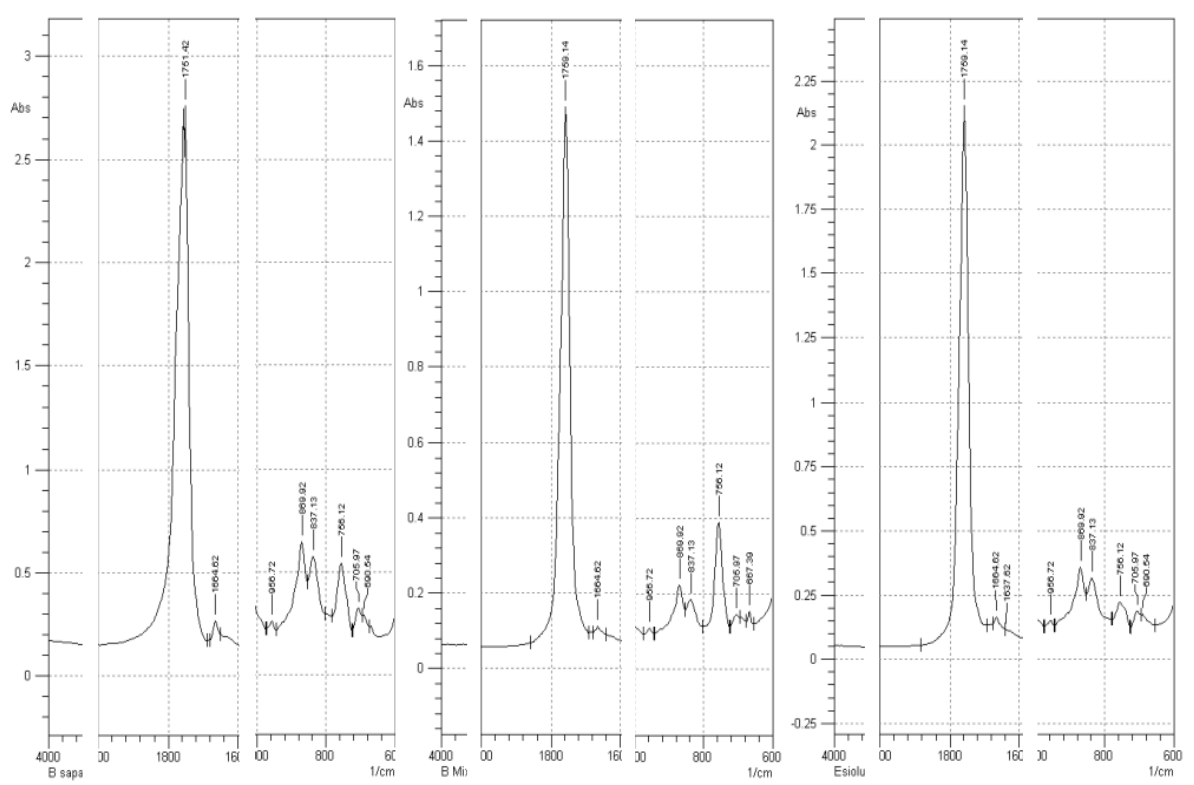

Figure 3. FTIR spectra for the two blends and a control physical mixture: (Left): ENR/PLA physical mixture of unprocessed polymers. (Centre): ENR/ PLA melt mixed polymers, i.e. binary Blend B. (Right): ENR/ PLA compatibilized Blend E.

The data in Table 2 show that there is a considerable discrepancy from the theoretical conversion of epoxy groups for the grafting reaction outlined in Figure 1, which is estimated 
to be around $15 \%$. This is considerably lower than the values obtained for the blends and the difference has been attributed to the formation of large amounts of vicinal diols (i.e. $\mathrm{COH}$ CHOH groups) [26].

Table 2: Data extracted from FTIR spectra

\begin{tabular}{|c|c|c|c|c|}
\hline $\begin{array}{l}\text { Absorbance peak height / } \\
\text { Sample description }\end{array}$ & $\begin{array}{l}\text { Carbonyl groups } \\
\left(1750 \mathrm{~cm}^{-1}\right)\end{array}$ & $\begin{array}{l}\text { Epoxy groups } \\
\left(870 \mathrm{~cm}^{-1}\right)\end{array}$ & $\begin{array}{l}\text { Absorbance Ratio } \\
\text { Epoxy / PLA }\end{array}$ & $\begin{array}{l}\text { Epoxy conversion } \\
\text { (\%) }\end{array}$ \\
\hline ENR/PLA physical mixture & 2.61 & 0.54 & 0.21 & 0 \\
\hline Binary Blend B & 1.43 & 0.17 & 0.12 & 43 \\
\hline Compatibilized Blend E & 2.10 & 0.30 & 0.14 & 32 \\
\hline Blend B+JM physical mixture & 0.45 & 0.06 & 0.13 & 37 \\
\hline
\end{tabular}

Furthermore, the results in Table 2 show that the presence of the Jeffamine component in the compatibilizer brings about a significant reduction in the conversion of epoxy groups, which may be ascribed to a reduction in the catalytic activity of the terminal carboxylic acid groups in the PLA component of the blend, due to the possible formation of corresponding ammonium salts, as indicated also by observations on the torque recorded during mixing of PLA with small quantities of Jeffamine M600 (not shown for brevity). It is worth noting also that the conversion of epoxy groups for the physical mixture of binary Blend B with $15 \%$ Jeffamine (equivalent to the amount in the compatibilized Blend E) corresponds to the estimated value results from a dilution effect. This confirms that no further conversion of epoxy groups has taken place in the electrospinning of the fibres.

\section{Fibre formation and mat density}

The optimum conditions for the ENR/PLA binary Blend B were found to be respectively 9.5 $\mathrm{kV}$ voltage, $15 \mathrm{~cm}$ distance and $1.9 \mathrm{~mL} / \mathrm{hr}$ flow rate, whereas for the compatibilized Blend $\mathrm{E}$ and the physical mixture of binary Blend B with Jeffamine were $10.5 \mathrm{kV}$ voltage, 22cm distance and $2.0 \mathrm{~mL} / \mathrm{hr}$ flow rate. Examples of elastomeric fibres produced under different conditions from the compatibilized blend of ENR and PLA (compatibilized Blend E) are shown in Figure 4. Note, however, that the mat density differences observed between the 
samples are not quantitative since the process time for fibre collection was not exactly the same for the various cases.

No "gel" particles were visible in the solution of all systems studied and, therefore, the hypothesis on the steric hindrance by the $\mathrm{CH}_{3}$ groups for cross-linking reactions, shown in the scheme in Figure 1, can be considered to have been verified. However, it should be noted that in previous work [24] a very high level of gelation was obtained with the use of dodecyl succinic anhydride as a cross-linking agent ENR50, which contains a nominal 50 mol\% epoxide groups. The discrepancy is likely to due to the greater accessibility of the $\mathrm{COOH}$ groups derived from the anhydride for interacting with the $\mathrm{OH}$ groups of the ENR chains than the NH group of the secondary amine chains of the grafted Jeffamine component.

All solutions were spun without prior filtration to remove any impurities present as microsuspended particles, such as traces of residual proteins in the ENR. At a flow rate of 2 $\mathrm{mL} /$ hour the estimated velocity of the jet at the exit is around $2 \mathrm{~mm} / \mathrm{s}$, which gives an average residence time of the solution molecules in the needle in the region of $40 \mathrm{~s}$. For the examples of fibres shown in Figure 1 the flow rate and applied voltage were kept constant so that the "polarization" (charge injection) time in the exiting jet is the same in all cases and the amount of charges, accumulated during the flow through the needle of the syringe, is also the same at a given applied voltage and flow rate. Increasing the distance of the collector from the needle tip only alters the strength of the electric field and the spatial distribution of the electrical stress and the time available for the evaporation of the solvent.

In preliminary studies on fibre formation it was found that the best conditions were determined primarily by the applied voltage. At low voltage there are insufficient charges in the jet to trigger the splaying of filament (see later), while at high voltages the jet become too unstable for formation of the Taylor cone. 

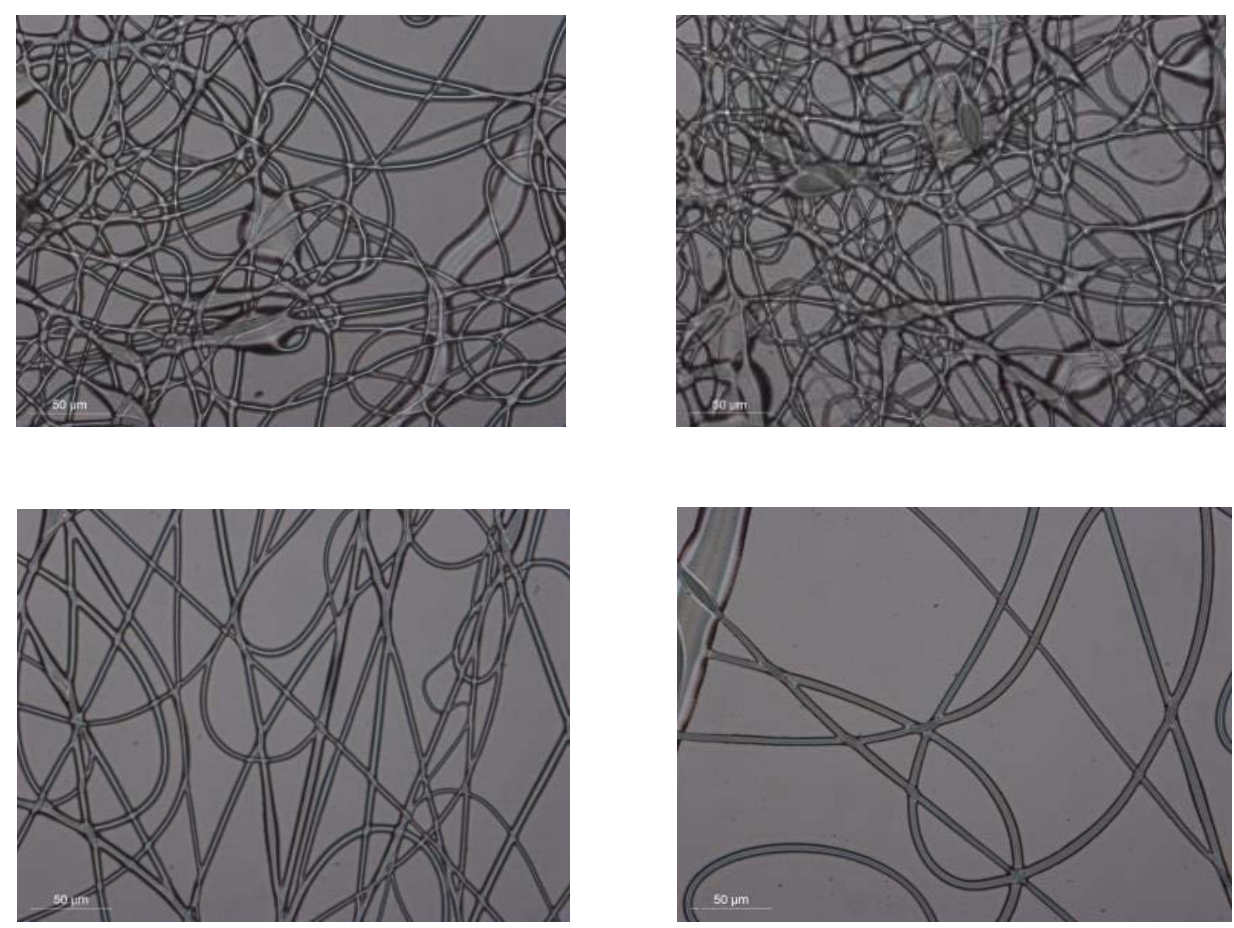

Figure 4. Fibres produced from compatibilized Blend $\mathrm{E}$ during runs at $10.5 \mathrm{kV}$ and capillary flow rate equal to $2.0 \mathrm{~mL} /$ hour, using different target distance: Top left $=14 \mathrm{~cm}$, Top right $=$ $18 \mathrm{~cm}$, Bottom left $=22 \mathrm{~cm}$, Bottom right $=24 \mathrm{~cm}$.

The optical micrograph of the mats in Figure 4 produced at the shortest distance reveals the presence of large filaments as well as large "gel” beads from which emerge several splayed fibres. Reneker and Chun [27] have identified four regions between the syringe needle tip and the collector:

a) The base as the region at the exit, which is a tapered cone in which the axial velocity of the liquid increases as the polymer is accelerated along the axis of the jet under the influence of the longitudinal stress.

b) The jet corresponds to the region beyond the base where the electrical forces continue to accelerate the "polymer liquid" and to stretch the jet.

c) Splaying occurs in a region in which the radial forces from the electrical charges carried by the jet become larger than the cohesive forces within the jet.

d) The collection region is where the jet is stopped by an earthed surface and the formed fibres are accumulated or continually removed by a rotating device. 
The above authors, however, have not discussed the state of the polymer solution at the point where splaying takes place. In many cases, however, the formation of fibres is presented as single filamentary products from the exit of the needle of the syringe to the collecting device. More recent authors have invoked the concept of chain entanglement inherent to solutions of high molecular weight polymers as a controlling parameter for the formation of fibres. In using polymer solutions under these conditions there will be a very rapid increase in viscosity with increasing polymer concentration, resulting from the evaporation of the solvent at the capillary exit. A power law relationship with exponent between 5 and 6 has been reported $[28,29]$.

An examination of the appearance of the fibres in the micrographs in Figure 4 confirms that that splaying has taken place in the formation of fibres, which would occur after a sufficient amount of solvent has evaporated to bring the physical state of the jet near towards the “critical gelation concentration” [30]. A clear demonstration of the role of gelation in electrospinning of polymers from solutions can be obtained from the experiments carried out by Crne et al [31]. These authors have produced physical gels from solutions of PMMA in dimethylformamide (DMF), which were used to make fibres by electrospinning through the needle of the syringe heated to temperatures well above the sol/gel transition temperature. They have found that continuous fibres could be produced at much lower polymer concentrations when using either iso-PMMA or syn-PMMA than the corresponding atactic (a-) polymer of same molecular weight, which they have attributed to the greater capability of the two stereoregular polymers to produce thermoreversible gels (i.e. lower critical polymer concentration for gelation) through formation of stereocomplex structures with solvent molecules.

The high viscosity of solutions of entangled polymers would exert a control on the ramifications of the jet stream (fibre splaying), as a result of the internal multidirectional explosive forces triggered by the high charge density acquired by the jet through a combination of charging sources, such as the polarization during flow through the needle of the syringe and the corona discharges produced through "air ionization" at the tip of the needle. The polymer solution at this point is likely to have reached the critical concentration required for the formation of a "gel”, which is brought about by nucleation events originating through a combination of chain entanglement and a thermodynamic drive for crystallization. Gelation of the solvated fibres brings about shape stability by exerting the required resistive 
forces in the longitudinal direction against the circumferential and radial surface energy forces resulting from the thermodynamic requirement to minimise surface area/volume ratio in forming spherical droplets. A general equation for the relationship between the change in surface area $(\Delta s)$ with time $(t)$ for a given volume $(v)$ as a function of the surface energy $(\gamma)$ would be $\Delta s=v \int(\varphi, \gamma / \eta) d t$, where $\varphi$ is a shape factor and $\eta$ is the viscosity. This equation stipulates that the conditions to achieve "absolute" dimension stability would be derived by setting $\Delta s=0$, which can only be satisfied through gelation, i.e. for $\eta \rightarrow \infty$, on the basis that the surface energy cannot be equal to zero.

The SEM images in Figure 5 show the appearance of typical samples collected from the ENR solution, at two levels of magnification. These clearly confirm that a single component ENR system does not lend itself to the formation of fibres over the entire range of conditions examined.
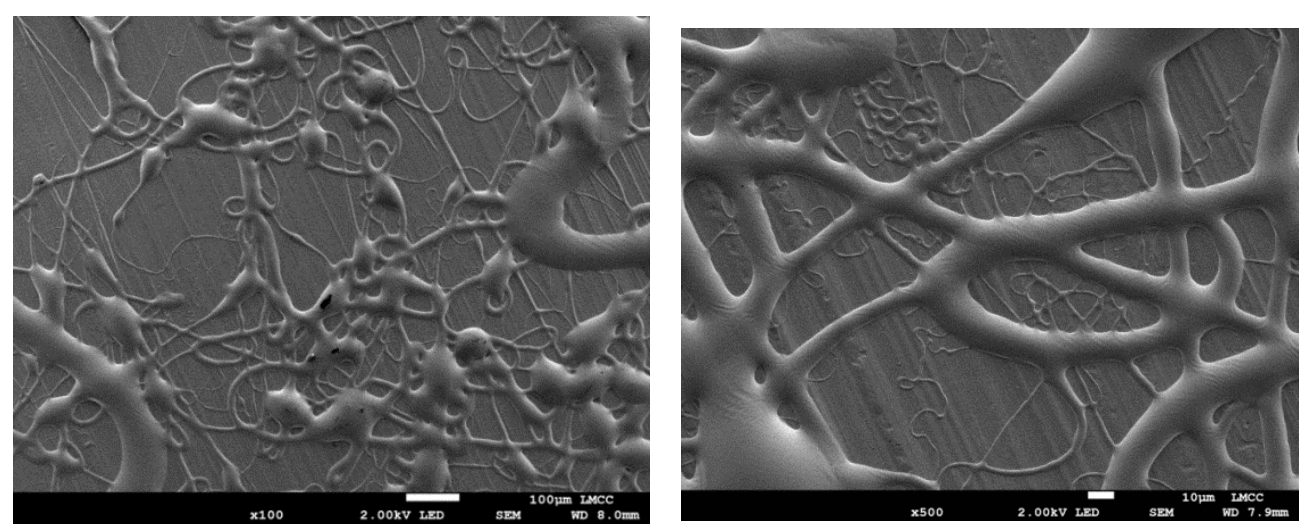

Figure 5. SEM micrographs of images of collected products from the solutions of ENR 25 in chloroform at low magnification (left) and high magnification (right).

It can be deduced that the difficulty to reach the required conditions in the electrospinning of the ENR solution is due to deficiencies arising from the low molecular weight of the polymer, in order to obtain a solutions with high viscosity to produce the required level of entanglements and from the lack of sufficient order in the molecular structure to produce a "gel". The molecular weight of the ENR used in the present work is quite low, estimated to be within the rage $40-80 \mathrm{kDa}$ due to the scission of polymer chains brought about by the 
oxidative epoxidation process and during melt mixing [32]. Furthermore, the crystalline domains in the original NR would have been largely destroyed by the introduction of epoxy groups, as they would have interrupted the cis- sequencing of the monomeric units along the molecular chain. Consequently the successful production of fibres from ENR/PLA blends has to be attributed to the presence of discrete hard domains, which brings about the necessary conditions for gelation of the fibres after splaying of the jet, in order to prevent the formation of globules under the influence of the surface tension (as discussed earlier). This deduction is supported by the work of Yang et al. [33] where an immiscible hard polymeric component (polymethyl methacrylate) was used to overcome the chain entanglement deficiencies of PDMS to achieve the conditions for fibre formation by electrospinning. Similarly Oktay et al. [34] have electrospun fibres from PDMS-poly(amic acid) block copolymers, which were subsequently thermally imidized to obtain PDMS-polyimide fibres in the form of mats.

It should be noted that the elastomeric fibres produced from single polymer systems reported by other authors were based on high molecular weight polymer grades, exhibiting also a certain degree of structural order. For instance, in the case of fibres produced from poly cis1,4 -isoprene the molecular weight was in the region of $400 \mathrm{kDa}$, as a synthetic grade [35], and even higher for natural rubber [15], both of which are known to contain crystalline domains. Accordingly, Choi et al. [8] have used a polybutadiene grade (BR) with molecular weight in the region of $520 \mathrm{kDa}$, which is essentially poly cis-1,4 -butadiene with a degree of crystallinity in the region of $20 \%$ [36].

In Figure 6 are compared the SEM micrographs of fibres at two levels of magnification for fibres produced from blends of ENR 25 with PLA, respectively binary Blend B, compatibilized Blend E and physical mixture Blend B + JM. The variation of fibre diameter for samples in the micrographs is shown alongside the images of the fibres in the form of histograms.
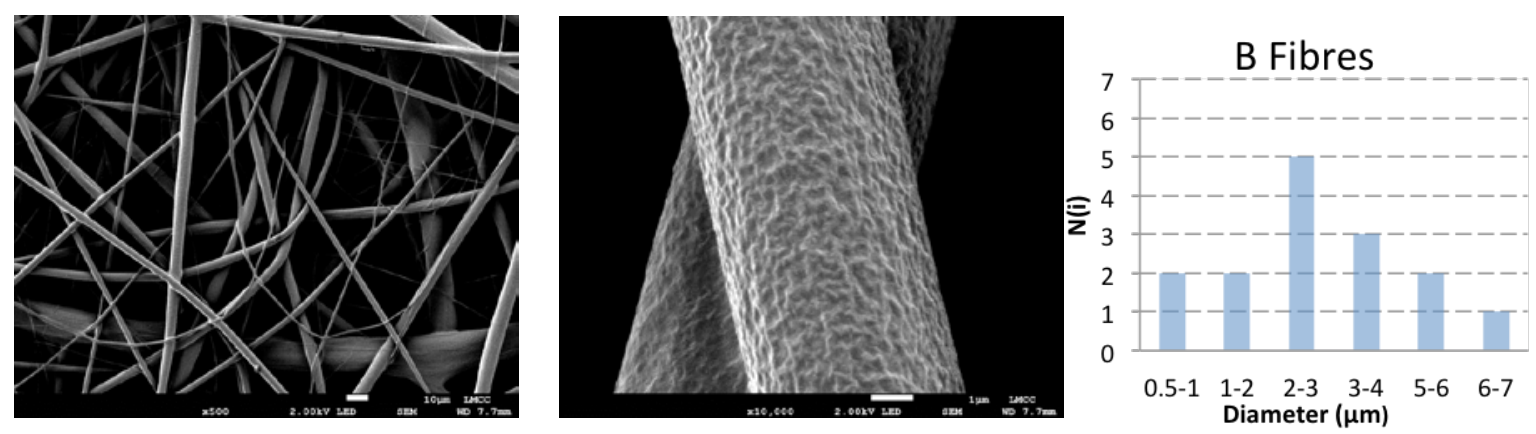

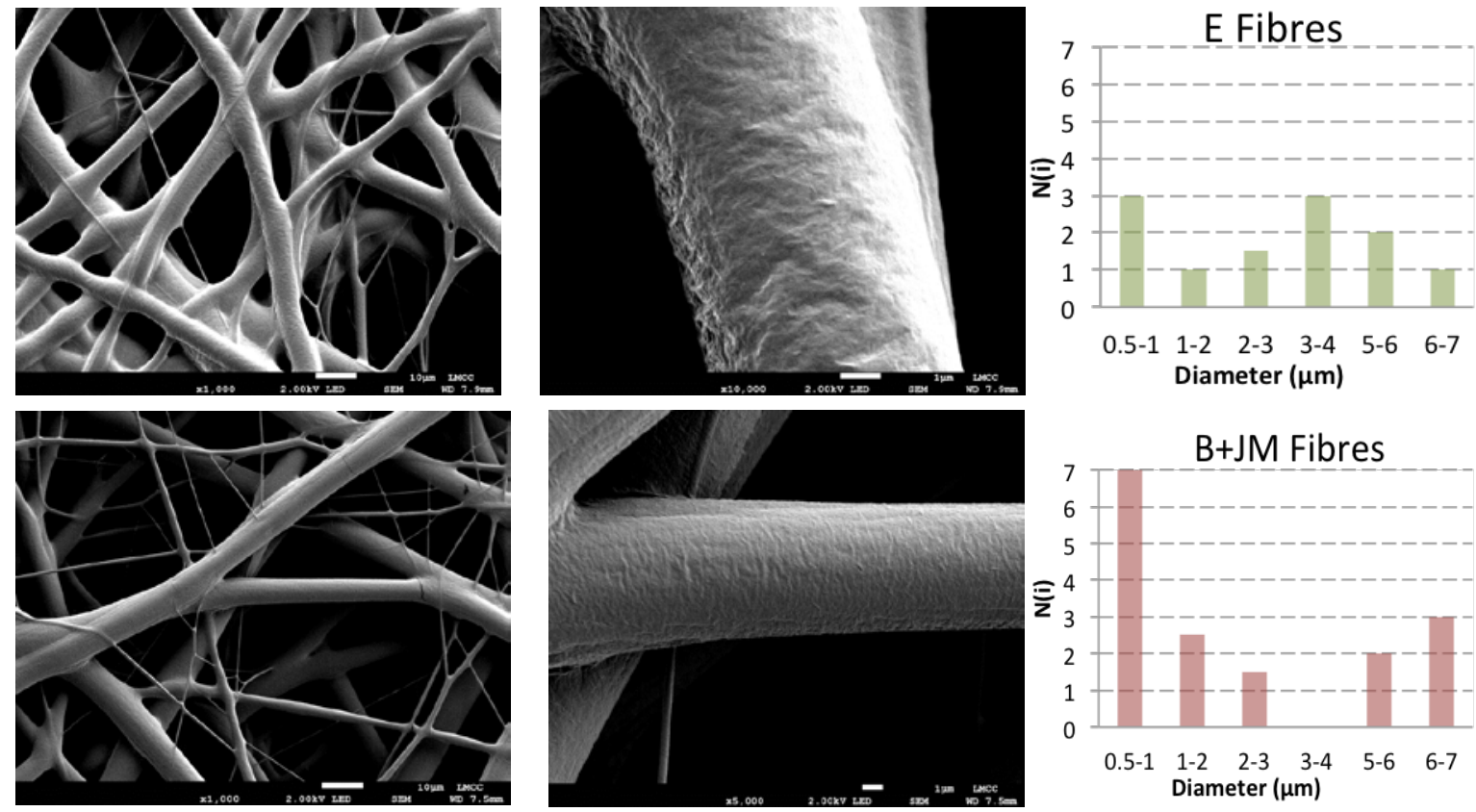

Figure 6. SEM micrographs at two levels of magnification for fibres produced from the three blend systems, with histograms of the diameter variation. Top: binary Blend B; Centre: compatibilized Blend E; Bottom: physical mixture of Blend B+JM. (Note the white scalebars in the images on the left correspond to $10 \mu \mathrm{m}$ and those on the right $1 \mu \mathrm{m}$ ).

The images in Figure 6 show the greater homogeneity of fibres produced from compatibilized Blend E (centre) and from the physical mixture Blend B + Jeffamine (bottom) than from the binary Blend B (top). The fibres from blends containing the Jeffamine modifier, either as a reaction compatibilized Blend $\mathrm{E}$ or as a physical mixture Blend $\mathrm{B}+\mathrm{JM}$, have a smoother surface finish than those produced from the binary Blend B. Since the surface of the "blobs" and the interconnected fibrillary elements collected during the electroprocessing of the neat ENR solution is very smooth, the surface protrusions visible on the surface of the fibres produced from the blends can only be attributed to the presence of PLA domains. The DSC data confirm that phase separation has occurred during the evaporation of the solvent.

The higher proportion of small diameter fibres produced with the incorporation of a compatibilizer in the solution mixture is indicative of a more effective splaying mechanism, brought about by the formation of smaller aggregates within the solution just prior to the onset of gelation. This provides a greater number of nuclei to trigger the splintering process for the formation of fine gelled fibres (splaying), emanating from the outer layers of the jet, 
which continues through successive steps until it is interrupted by the rigidity provided by thick layers of gel in the central regions.

The above interpretation of events for the formation fibres in electrospinning of polymer blends raises also questions about inter-fibre variability with respect to domain size and degree of crystallinity. The much higher evaporation rate accompanying the formation of the very fine fibres relative to that in the much thicker fibres can be expected to affect the morphology of the segregated domains, which would be reflected in the properties of individual fibres. Needless to say that the experimental verification would present insurmountable difficulties in the selective sampling of the fibres from the mats produced.

The thermograms in Figures 7 from the DSC thermal analysis and the summarized data in Table 3 confirm the existence of a two-phase morphology for the fibres produced from all three ENR/PLA blends. Note that the normalized enthalpy data for the PLA phase in the binary Blend $\mathrm{B}$ correspond to a degree of crystallinity in the region of $37 \%$, which is a typical value for this grade of PLA crystallized from the melt. Moreover, the Tg and the peak cold crystallization temperature (Tc) values are also similar to those obtained previously on processed neat PLA [25].

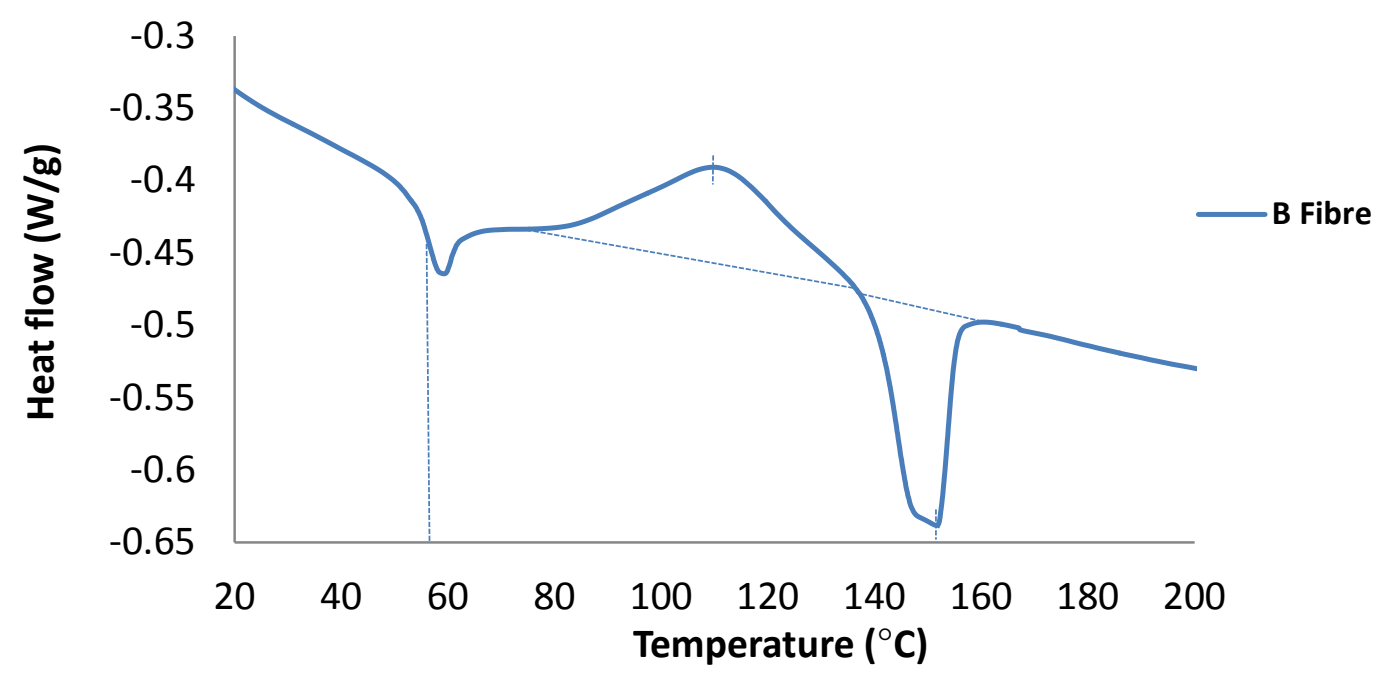



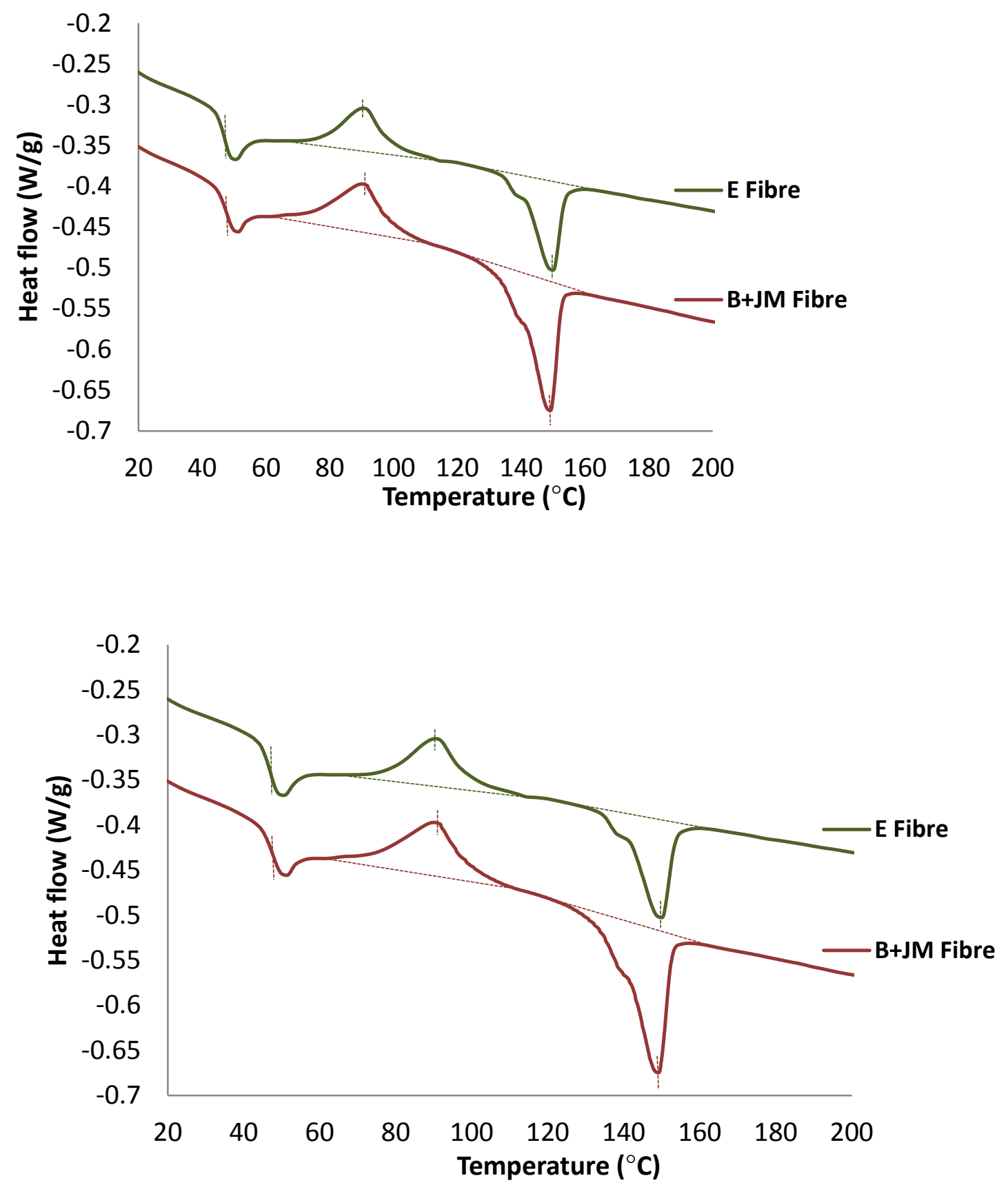

Figure 7. DSC thermograms of fibres electrospun from blends of ENR 25 and PLA. Top: Fibres produced from binary Blend B; Bottom: Fibres produced from compatibilized Blend $\mathrm{E}$ and Fibres produced from physical mixture of binary Blend B and Jeffamine.

Table 3: Summary of data obtained by DSC analysis carried out on the electrospun fibres and melt mixture of PLA with 2 \% Jeffamine (PLA+JM) 


\begin{tabular}{|l|c|c|c|c|c|c|}
\hline \multicolumn{1}{|c|}{ SAMPLE } & $T_{g}\left({ }^{\circ} \mathrm{C}\right)$ & $T_{c}\left({ }^{\circ} \mathrm{C}\right)$ & $T_{m(1)}\left({ }^{\circ} \mathrm{C}\right)$ & $T_{m(2)}\left({ }^{\circ} \mathrm{C}\right)$ & $\Delta H_{c}(\mathrm{~J} / \mathrm{g})$ & $\Delta H_{m}(\mathrm{~J} / \mathrm{g})$ \\
\hline Fibres from Blend B & 56.4 & 110.7 & N.A. & 151.4 & 9.32 & 10.49 \\
\hline Fibres from Blend E & 47.0 & 90.9 & 137.9 & 149.6 & 4.67 & 6.34 \\
\hline Fibres from Blend B+JM & 48.1 & 90.6 & 138.3 & 148.9 & 5.12 & 8.72 \\
\hline Melt mixture PLA + JM & 49.2 & 105.1 & 142.0 & 154.3 & $(6.54)^{*}$ & $(7.05)^{*}$ \\
\hline
\end{tabular}

Note: 1) *Values in brackets are normalized to $30 \mathrm{w} \%$ in correspondence with the amount of PLA in the fibres; 2) N.A. = Not Applicable

In the present study, the thermogram for an ad hoc melt mixture of PLA with 2 w\% Jeffamine displays features similar to those found for fibres produced from the blends containing Jeffamine, which display a reduction in $\mathrm{Tg}$ (from 56.1 to $49.2{ }^{\circ} \mathrm{C}$ ) and reveal the appearance of a lower Tm shoulder in the melting.

The DSC thermal data relevant to the crystallization of the fibres in the electrospinning process are summarized in Table 4.

Table 4 : Enthalpy data related to the crystallization of the PLA phase in the fibres.

\begin{tabular}{|c|c|c|c|}
\hline Crystallization parameter $(X)$ & $\begin{array}{l}\text { Extent of crystallization of fibres } \\
\text { relative to maximum achievable } \\
\text { for the system } \quad(\mathbf{X c}) \mathbf{i}(\%)\end{array}$ & $\begin{array}{l}\text { Extent of crystallization of } \\
\text { fibres relative to fibres from } \\
\text { binary Blend B } \quad(\mathbf{X c}) \boldsymbol{r}\end{array}$ & $\begin{array}{l}\text { Maximum achievable crystallization } \\
\text { in fibres relative to fibres from } \\
\text { binary Blend B } \quad(\boldsymbol{X m}) \boldsymbol{r}(\%)\end{array}$ \\
\hline Sample // Equation for $(X)$ & {$\left[\left(\Delta H_{m}\right) i-\left(\Delta H_{c}\right) i\right] \div\left(\Delta H_{m}\right) i$} & $\begin{array}{r}{\left[\left(\Delta H_{m}\right) i-\left(\Delta H_{c}\right) i\right] \div} \\
{\left[\left(\Delta H_{m}\right) B-\left(\Delta H_{c}\right) B\right]}\end{array}$ & $\left(\Delta H_{m}\right) i \div\left(\Delta H_{m}\right) B$ \\
\hline Fibres from Blend B & 11.1 & 1 & 100 \\
\hline Fibres from Blend E & 26.3 & 1.43 & 60.4 \\
\hline Fibres from Blend B+JM & 41.3 & 3.08 & 83.1 \\
\hline
\end{tabular}

These show that the presence of Jeffamine in the polymer blends increases the extent of solvent induced crystallization of the fibres $\left(X_{C}\right)$ i relative to the maximum achievable for the system considered and, in particular, the effect is greater when it is in the form of a "free" plasticizer than when is pre-grafted on the ENR (i.e. ENR-g-JM). The relative rates of solvent induced crystallization can be estimated from the enthalpy data in Table 3 as the ratio of the extent of crystallization of the fibres for the ternary system to the value for fibres of the binary Blend B $\left(X_{c}\right) r$, which is 1.43 for the compatibilized Blend B and 3.08 for the physical mixture Blend B+JM. Furthermore, the depression of the maximum degree of crystallinity of the PLA component achievable for the ternary blends relative to the highest extent of 
crystallization that can be obtained in the binary blend (corresponding also to the value for neat PLA processed under the same conditions) is much less when the Jeffamine is used as a free plasticizer in the physical mixture (83.1\%) than when is present as a chemically bound component of the compatibilizer ENR-g-JM (60.4\%). [See values for (Xm)r in Table 4].

It is worth noting that polypropylene glycol (PPG) has been also been found by other authors to affect the overall rate of crystallization, as well as the rate of growth of spherulites, when used as plasticizer for PLA [37-40].

\section{Inferences from DSC data at low temperatures}

In Figure 8 are shown the thermograms for systems that were used in the production of the electrospun fibres obtained from the DSC analysis at low temperatures across the glassrubber transition of the ENR phase. The intersection point of the extrapolated part of the trace representing the initiation of the transition $\left(\mathrm{Tg}{ }_{(i)}\right)$, as well as the temperature value at the minimum in the trace representing the end of the transition and the starting of the relaxation of the enthalpy for the physical ageing ( $\operatorname{Tg}(\mathrm{f})$ ), are shown in Table 5 . Note that the recorded Tg value for processed ENR25 of this study is slightly higher than the values reported by the manufacturers and from measurements carried on the same batch of the pristine elastomer sample. This discrepancy can be attributed to the formation of vicinal $\mathrm{OH}$ groups through reactions with water moisture during mixing [41], but it could also be due to the differences to the method and the heating rate used in the measurements.

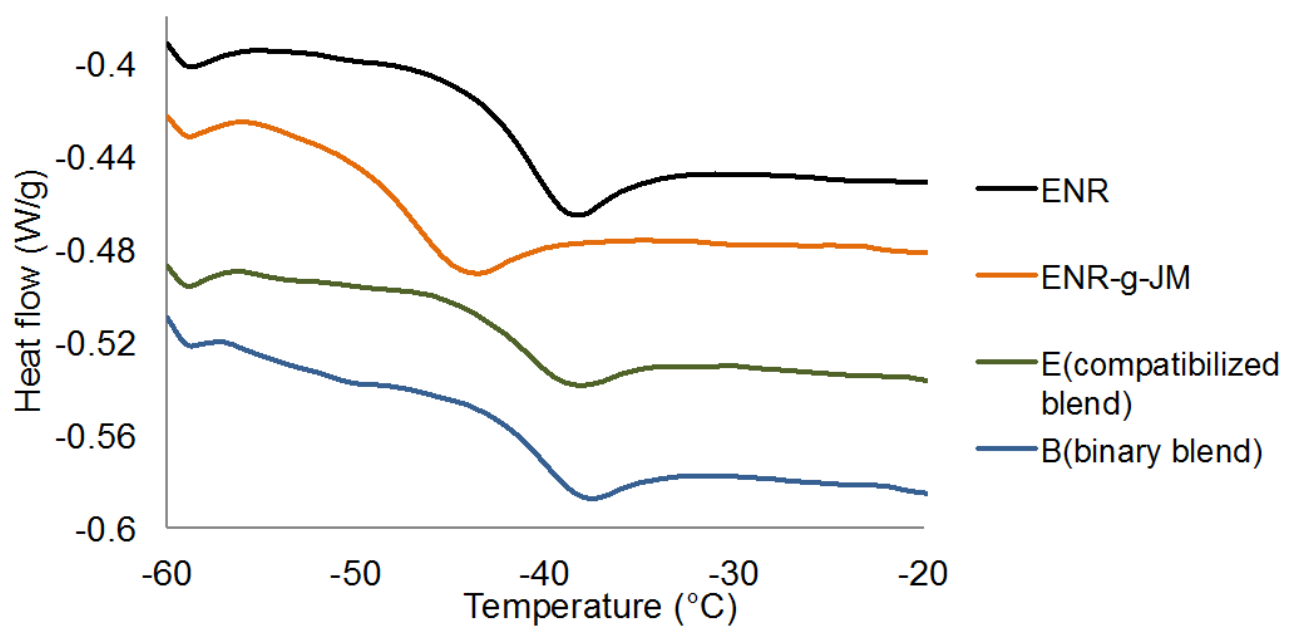


Figure 8. Low temperature DSC thermograms for systems used in the production of electrospun fibres.

The substantial shifting and broadening of the glass-rubber transition region for the system ENR-g-JM, identifiable in Figure 8, clearly demonstrate the internal plasticization effect resulting from the reaction of Jeffamine with ENR25. Since the Tg of ENR 25 is very close to the melting point of Jeffamine a non-interactive solubilisation mechanism alone would not be expected to bring about any change in the Tg of the polymer.

Table 5. Summarised DSC data extracted from the thermograms in Figure 9.

\begin{tabular}{|l|c|c|}
\hline Sample & $\mathbf{T g}_{(\mathbf{i})}\left({ }^{\mathbf{0}} \mathrm{C}\right)$ & $\mathbf{T g}_{(\mathbf{f})}\left({ }^{\mathbf{0}} \mathbf{C}\right)$ \\
\hline Processed ENR25 & -43.2 & -38.0 \\
\hline ENR-g-JM & -49.7 & -44.0 \\
\hline Binary Blend B & -42.2 & -37.5 \\
\hline Compatibilized Blend E & -45.1 & -39.0 \\
\hline
\end{tabular}

In examining the $\mathrm{Tg}$ data in Table 5 one notes that the reference glass transition temperature values $\left(\mathrm{Tg}_{(\mathrm{i})}\right.$ and $\left.\mathrm{Tg}_{(\mathrm{f})}\right)$ for the processed ENR25 and the binary Blend $\mathrm{B}$ are quite close, even though the slightly lower values for the processed ENR25 could be significant [24]. A distinctly larger reduction in the $\operatorname{Tg}_{(i)}$ value, on the other hand, is observed for the compatibilized Blend E, which is a reflection of the effect of the lower and broader glass transition of the component ENR-g-JM. Since a reduction in Tg values in the compatibilized Blend $\mathrm{E}$ is experienced for both the rubber phase and the PLA phase, the observed effects confirm unequivocally the efficient compatibilization of blends of ENR25/PLA brought about by addition of ENR-g-JM. 
The scheme in Figure 9 indicates that a thermodynamic drive is expected for the migration of "free” Jeffamine species into the PLA component of the binary Blend B, due to the stronger interactions between the amine groups in Jeffamine with the carboxylic end groups in the PLA, towards the formation of the corresponding ammonium salt than with the oxygen of the epoxy group in ENR25. These associations are highly restricted when Jeffamine is chemically bonded to the ENR chains in the ENR-g-JM compatibilizer and can, therefore, be taken as a contributory factor for the reduced effect on the extent of crystallization in the fibres.

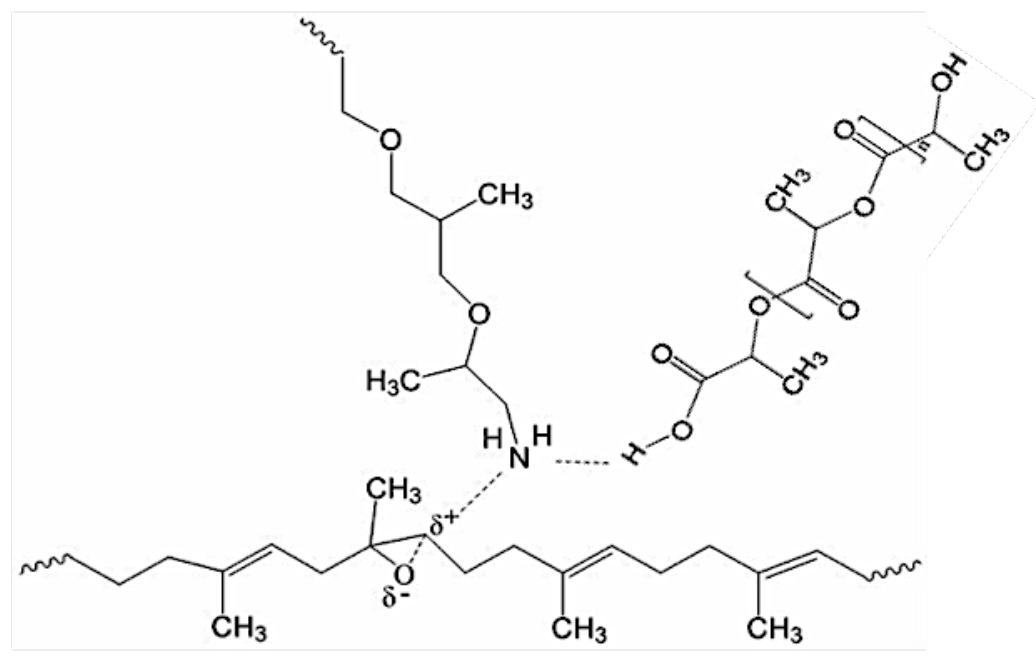

Figure 9. Interactions of Jeffamine M600 with carboxylic acid groups in PLA and epoxy groups in ENR25.

\section{Further considerations on surface texture}

The formation of surface roughness features has been observed by several authors for fibres electrospun from a variety of polymers. Celebioglu and Uyar [42] have produced highly porous fibres from cellulose acetate (CA) solutions using a combination of low boiling solvents and have shown that the surface roughness results from the rupture of the large quantity of voids in the outer regions of the fibres. It was noted that the severity of the surface roughness decreased with increasing the polymer concentration of the solution used to 
produce the fibres. Both porosity and surface roughness features were absent when one of the low boiling solvent, dichloromethane (B.Pt. $=40{ }^{\circ} \mathrm{C}$ ), was replaced with a high boiling solvent, dimethyl acetamide (B.Pt. $=165{ }^{\circ} \mathrm{C}$ ). Surface porosity has also been observed by Katsogiannis et al. [43] in studies of on electrospinning of polycaprolactone using a mixture of chloroform and dimethyl sulfoxide solvent.

With regard to the important role of the volatility of solvents it is worth noting that Han et al. [44] have obtained non-porous CA fibres solutions in mixtures of water and acetic acid at 10 - 15\% concentration. The role of the solvent in determining the primary and hierarchical structure of fibres has also by demonstrated by Li et al. [45] in the electrospinning of solutions of polymethyl methacrylate (PMMA). The addition of a hydrophilic solvent, such as DMF, was found to play an important role in the events on the surface of the fibres due to the thermodynamic instabilities resulting from leaching out of quantities of DMF through solubilisation in water from the atmosphere, which causes a localized desolubilization of the polymer and the formation of surface roughness through differential solvent desorption rates. However, porosity and surface roughness were also observed with the use of more volatile hydrophobic solvents, such as chloroform at high solution concentrations (20\%). A study by Gasper et al. [46] has shown that the surface roughness, in the form of a multitude of connected craters, on fibres electrospun from polystyrene (PS) solutions in tetrahydrofuran (THF) is due the environmental humidity at levels greater than $25 \%$. The condensation of small droplets of water, at different sites over the surface of the jet, causes disturbances in the solvent evaporation rate over the surface area of the fibres, which gives rise to the formation of myriad imprints resulting from localized events related to the contact with water droplets. Although explanations were not provided the observed effects must be related to the hydrophobic nature of the fibres, which impedes the spreading of water over the surface and to the "gel" state of the fibres in preventing the self-levelling of the protrusions through molecular flow by the surface energy forces.

In the majority of the reports the surface roughness has been connected with the porosity in the bulk of the fibres, which were all produced from single polymers using a mixture of solvents. The formation of pores has been explained has been attributed to the formation of a "dense” skin [40], which creates a barrier for the evaporation of the solvent and gives rise to the nucleation of voids within the bulk. Although the systems of this study are different from those reported in the literature a close inspection of the surface of the fibres suggest that there 
could be some commonality with respect of the formation of voids as a contributory factor. The micrographs in Figure 10 show the appearance of the surface of the fibres produced, respectively from a compatibilized ENR/PLA blend (binary Blend B + JM) and for the binary Blend B (non-compatibilized). Not only does the latter exhibit a much rougher surface but it displays also the presence of many distinct "pin holes", which are absent on the much smoother surface of the fibres from the physical mixture Blend B + JM. This specific feature indicates that voids can still form even after "gelation" of the fibres, however, the absence of similar "pin holes" on the fibres produced from both compatibilized Blend B and the physical mixture Blend B + JM suggest the morphological structure may play an important role in relation to the evaporation rate of the solvent.
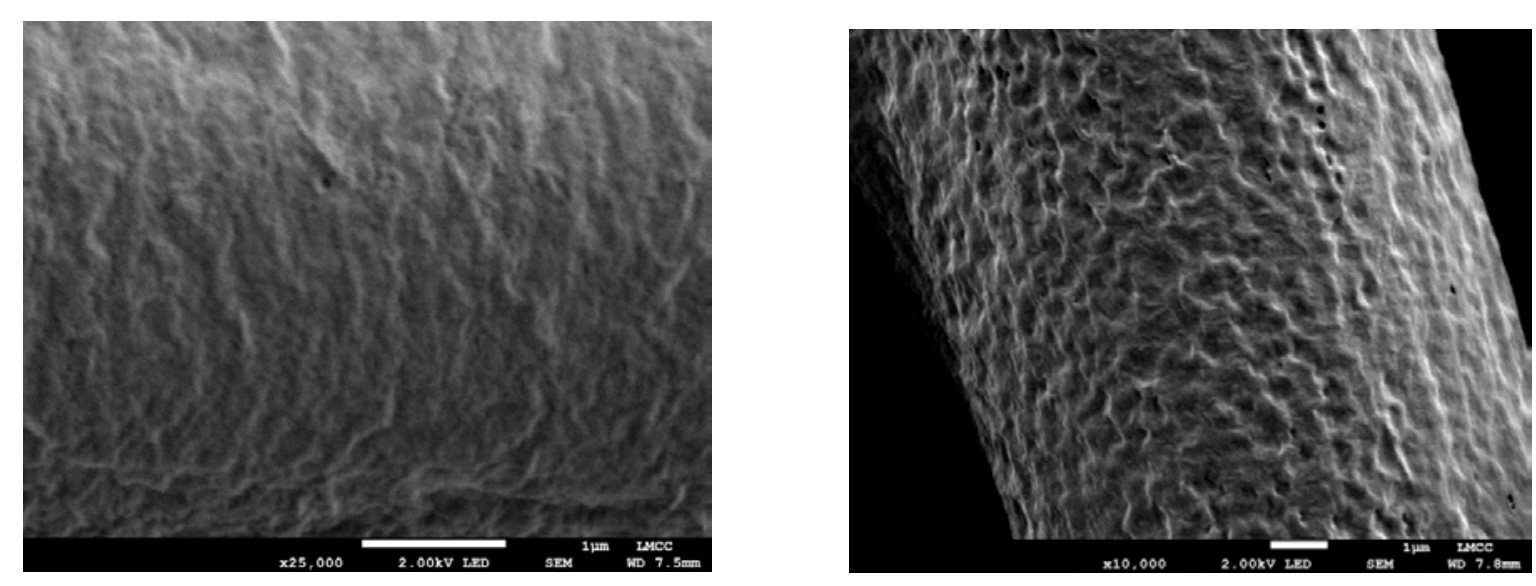

Figure 10. Topography of the surface of electrospun fibres; Left - physical mixture of Blend B + JM) (smooth surface); Right - binay Blend B (rough surface, large number of pin holes).

Although the extent of process induced crystallization of the PLA phase in the fibres is greater for the latter two systems than in the case of the fibres from the binary Blend $B$, the compatibilization induced by the Jeffamine component is expected to reduce the size of the PLA domains, as well as promoting the formation of co-continuous phases in accordance to well established principles of polymer blends. This type of morphology would exert a control on the topography of the surface of the fibres by reducing the size of the asperities resulting from differential contractions between the constituent phases during the evaporation of the 
solvent. The more shallow topography of the protrusion on the surface of the fibres from the physical mixture Blend $\mathrm{B}+\mathrm{JM}$ relative to the compatibilized Blend $\mathrm{E}$, discernible in the micrographs in Figure 6, suggests that the enhanced crystallization rate resulting from the free Jeffamine impedes the growth of the PLA domains after phase separation from the solution. Note that the low Tg of the rubbery matrix of the blends used has not made it possible to obtain SEM micrographs for a more thorough characterization of the morphological state due to the experimental difficulties of inducing brittle fracture through the fibres under cryogenic conditions.

The pinholes on the surface of the fibres from binary Blend B appear to be located mostly in the troughs between the arrays of peaks, suggesting that they may result from a faster evaporation of the solvent in coincidence with the location of the rubbery domains. A more uniform solvent evaporation, on the other hand, would take place in fibres produced from the two systems containing Jeffamine component, which would reduce the propensity of void formation in sites between the hard and soft domains. The presence of a few and well-defined pin holes (or craters) are also visible on the surface of the smother fibres in the micrograph on the left.

\section{Conclusions}

A compatibilizer (ENR-g-JM) for blends of an epoxidized natural rubber (ENR25) and a crystalline grade of polylactic acid was produced by reacting in a Haake mixer a monoamine terminated polyethylene glycol (Jeffamine M600) with ENR25 at molar ratio 1:12.

Blends of ENR25 with PLA, at weight ratio 70:30, were produced both as a binary blend (binary Blend B) and in combination with a small amount of compatibilizer ENR-g-JM (compatibilized Blend E). Solutions in chloroform were evaluated for the production of fibres by electrospinning, which were then examined by thermal analysis as well as for dimension measurements and surface texture examinations.

While solutions containing only ENR25 were not conducive to the electrospinning of fibres, the presence of PLA in blends made it possible for fibres to be produced over a wide range of operating conditions. The favourable response acquired by the latter systems is attributed to 
the stability of the geometry of fibres subsequent to splaying of the solution jet, which can be presumed to arise from the gelation of the fibres. The gel state of the solvated fibres provide the required axial forces to oppose the circumferential and radial shrinkage resulting from the inherent surface energy in the thermodynamic drive to minimise the free energy of the system.

The fibres obtained from binary Blend B displayed a considerable level of surface roughness, featuring as a consistent pattern along the entire length of the fibres, which is attributed to the differential evaporation rate of the solvent from the two constituent phases.

The fibres containing Jeffamine, either chain-bonded species (ERN-g-JM) or as a "free" plasticizer (binary Blend B $+\mathrm{JM}$ ), display a much smoother surface texture due to the reduction in the dimensions of the PLA domains and to the likely co-continuity of the constituent phases, which provides a more uniform evaporation rate of the solvent from the various constituent domains of the "gelled" fibres.

It can also be concluded that although the interpretation of the splaying mechanism and the related formation of larger quantities of fine fibres resulting from compatibilization of the components of the ENR/PLA blend examined can only be of an exploratory nature, the related observations brings out an awareness of the wider role of compatibilizing agents in the electrospinning of polymer blends.

\section{Acknowledgments}

The authors wish to thank David Grandy for performing the DSC tests at low temperature and the Tun Abdul Razak Research Centre for the donation of large quantities of Epoxidized Natural Rubber.

\section{References}

[1]. W.E. Teo, S. Ramakrishna, A review on electrospinning design and nanofibre assemblies, Nanotechnology, 2006, 17(14): R89. 
[2]. T.D. Brown, P.D. Dalton, D.W. Hutmacher, Melt electrospinning today: An opportune time for an emerging polymer process. Progr. Polym. Sci., 56 (2016) 116166.

[3]. C. J. Luo, S.D. Stoyanov, E. Stride, Electrospinning versus fibre production methods: from specifics to technological convergence, Chemical Society Reviews, 2012, 41(13): 4708-4735.

[4]. J.M. Deitzel, J. Kleinmeyer, D. Harris, N.C. Beck Tan, The effect of processing variables on the morphology of electrospun nanofibers and textiles, Polymer 42 (2001) 261-272

[5]. M.D Edwards, G.R. Mitchel, S.D. Mohan, R.H. Olley, Development of orientation during the electrospinning of poly(e-caprolactone), Eur. Polym. J.,46 (2010) 1175-1183.

[6]. S. Sithornkul, P. Threepopnatkul, Control of Mechanical Properties and Permeability of Electrospun Natural Rubber with Different Composite Systems, Advanced Materials Research 2010, 93: 619-622.

[7]. W. Rungswang, M. Kotaki, T. Shimojima, G. Kimura, S. Sakurai, S. Chirachanchai, Existence of microdomain orientation in thermoplastic elastomer through a case study of SEBS electrospun fibers, Polymer (2011) 52, 844-853

[8]. S.-S. Choi, J.-P. Hong, Y. S. Seo, S. M. Chung, C. Nah, Fabrication and Characterization of Electrospun Polybutadiene Fibers Crosslinked by UV Irradiation, $J$ Appl Polym Sci 101 (2006) 2333-2337.

[9]. M. Tian, Q. Hu, H. Wu, L. Zhang, H. Fong, L. Zhang, Formation and morphological stability of polybutadiene rubber fibers prepared through combination of electrospinning and in-situ photo-crosslinking, Materials Letters 65 (2011) 3076-3079 
[10]. E. Mele, Electrospinning of natural polymers for advanced wound care: towards responsive and adaptive dressings, J. Mater. Chem. B, 4 (2016) 4801-4812.

[11]. J. Wu, N. Wang, Y. Zhao and L. Jiang, Electrospinning of multilevel structured functional micro-/nanofibers and their applications, J. Mater. Chem. A, 1 (2013) 7290-7305.

[12]. E. Mele, J. A. Heredia-Guerrero, I. S. Bayer, G. Ciofani, G. G. Genchi, L. Ceseracciu, A. Davis, E. L. Papadopoulou, M. J. Barthel, L. Marini, R. Ruffilli and A. Athanassiou, Zwitterionic Nanofibers of Super-Glue for Transparent and Biocompatible Multi-Purpose Coatings, Sci. Rep., 5 (2015) 14019.

[13]. E. Mele, I. S. Bayer, G. Nanni, J. A. Heredia-Guerrero, R. Ruffilli, F. Ayadi, L. Marini, R. Cingolani and A. Athanassiou, Biomimetic approach for liquid encapsulation with nanofibrillar cloaks, Langmuir, 30 (2014) 2896-2902.

[14]. X. Hao, C. Bai, Y. Huang, J. Bi, C. Zhang, H. Cai, X. Zhang. L. Du, Preparation of cis-1, 4-Polyisoprene Electrospun Microfibers. Macromolecular Materials and Engineering, 295 (2010) 305-309.

[15]. L. M. Manzine Costa, L. H. Capparelli Mattoso, M. Ferreira, Electrospinning of PCL/natural rubber blends, J. Mater. Sci. 48 (2013) 8501-8508.

[16]. I. Cacciotti, J. N. House, C. Mazzuca, M. Valentini, F. Madau, A. Palleschi, P. Straffi, F. Nanni, Neat and GNPs loaded natural rubber fibers by electrospinning: Manufacturing and characterization, Materials and Design, 88 (2015) 1109-1118.

[17] J. G. L. Cosme, M.S. Vanessa, V.M. Silva, R.R.C. Nunes, P.H.S. Picciani, Rubber Blends Processed by Electrospinning: Morphological, Structural and Thermal Properties, Materials Sciences and Applications, 7 (2016) 210-219).

[18]. C. S. L. Baker, I. R. Gelling and R. Newell, Epoxidized natural rubber, Rubber Chem. Technol. 58 (1985) 67-85. 
[19]. M. Pire, S. Norvez, I. Iliopoulos, B. L. Rossignol and L. Leibler, Epoxidized natural rubber/dicarboxylic acid self-vulcanized blends, Polymer 51 (2010) 5903.

[20]. M. Yikmis, Secretion and transcriptional regulation of the latex-clearing protein, Lcp, by the rubber-degrading bacterium Streptomyces sp. strain K30, Appl. Environ. Microbiol., 74 (2008) 5373-5382.

[21]. C. Gallert, Degradation of latex and of natural rubber by Streptomyces strain La7, Systematic and applied microbiology, 23 (2000) 433-441.

[22]. L. Mascia, P. Russo, M. Lavorgna, L. Verdolotti, J. Clarke, A. Vignali, D. Acierno, Epoxidized natural rubber: Exploring the potential of an old elastomer, AIP Conference Proceedings, 1599 (2014) 26-29.

[23]. X. Hu, A. Fukutani, X. Liu, K. Kimbara, F. Karvay, Isolation of bacteria able to grow on both polyethylene glycol (PEG) and polypropylene glycol (PPG) and their PEG/PPG dehydrogenases, Appl. Microbiol. Biotechnol., 73 (2007) 1407 - 1712.

[24]. L. Mascia, J. Clarke, K.- S. Ng, K. S. Chua, P. Russo, Curing efficiency of Dodecyl Succinic Anhydride as a Cross-Linking Agent for Elastomer Blends Based on Epoxidized Natural Rubber, J. Appl. Polym. Sci., 132 (2015) 41448 (8) DOI:101002/app 41448

[25]. L. Mascia, B. Haworth, A.Vignali, R. Megna, D. Acierno , P. Russo, Thermal transitions and solidification kinetics of poly(lactic acid) and blends with epoxidized natural rubber, Thermochimica Acta, (2016), pp. 82-90 DOI information: 10.1016/j.tca.2016.04.004

[26]. L. Mascia, P. Russo, L.Verdolotti, J. Clarke, M. Lavorgna, D. Acierno, Probing the post-gelation reactions of epoxidized natural rubber cross-linked with dodecenyl succinic anhydride, Rubber Chemistry and Technology, 88 (2015) 560-573; 07/2015, DOI 105254/rct 1584888. 
[27]. D. H. Reneker and I. Chun, Nanometre diameter fibres of polymer, produced by electrospinning, Nanotechnology, 7 (1996) 216-223.

[28]. R. Casasola, N.L. Thomas, A. Trybala, S. Georgiadou, Electrospun polylactic acid (PLA) fibres: Effect of different solvent systems on fibre morphology and diameter, Polymer 55 (2014) 4728-4737.

[29]. R.H. Colby, L.J. Fetters, W.G. Funk, W.W. Graessley, Effects of concentration and thermodynamic interaction on the viscoelastic properties of polymer solutions. Macromolecules 24 (1991) 3873 - 3882.

[30]. B. Koltisco, A. Keller, M. Litt, E. Baer, A. Hilrner, Mechanical properties of thermoreversible gels, Macromolecules 19 (1986) 1207 - 1212.

[31] M. Crne, J. O. Park, M. Srinivasarao, Electrospinning physical gels: The case of stereocomplex PMMA, Macromolecules, 42 (2009) 4353-4355.

[32]. B. T. Poh and A. T. Yong, Dependence of peel adhesion on molecular weight of epoxidized natural rubber, The Journal of Adhesion, 85 (2009) 435-446, DOI: 0.1080/00218460903040941.

[33]. D. Yang, X. Liu, Y. Zhu, D. Zheng, H. Ma, Electrospinning of polydimethyl siloxane / poly(methylmethacrylate) nanofibrous membranes: fabrication and application in protein microarrays, Biomacromolecules, 10 (2009) 3335-3340.

[34]. B. Oktay, R.D. Toker and N. Kayman-Apihan, Superhydrophobic behaviour of polyimide-siloxane mats produced by electrospinning, Polymer Bulletin, 72 (2015) 28312842.

[35]. X. Hao, C. Bai, Y. Huang, J. Bi, C. Zhang, H. Cai, X. Zhang, L. Du, Preparation of cis1,4-Polyisoprene Electrospun Microfibers, Macromol. Mater. Eng., 295 (2010) 305-309. 
[36]. A.N. Gent and L-Q. Zhang, strain induced crystallization and strength of elastomer poly cis-1,4 -butadiene, J. Polym. Sci, Part B - Polymer Physics, 30 (2001) 811-817.

[37]. Z. Kulinski, E. Piorkowska, Crystallization, structure and properties of plasticized poly(L-lactide), Polymer 46 (2005) 10290 - 10300.

[38]. Z. Kulinski, E. Piorkowska, K. Gadzinowska, and M. Stasiak, Plasticization of Poly (Llactide) with Poly (propylene glycol), Biomacromolecules 7 (2006) 2128-2135.

[39]. H. Li, M. A. Huneault, Effects of nucleation and plasticization on the crystallization of poly(lactic acid), Polymer 48 (2007) 6855-6866.

[40]. S. McCarthy and X. Song, Biodegradable plasticizers for polylactic Acid, J. Appl. Med. Polymers, 6 (2002) 64-69.

[41]. S.-N. Gan, Z. A. Hamid, Partial conversion of epoxide groups to diols in epoxidized natural rubber, Polymer 38 (1997) 1953-1956

[42]. A. Celebioglu, T. Uyar, Electrospun porous cellulose acetate fibers from volatile solvent mixture, Materials Letters 65 (2011) 2291-2294.

[43]. K.A.G. Katsogiannis, G.T. Vladisavljevic, S. Georgiadou, Porous electrospun polycaprolactone (PCL) fibres by phase separation, Eur. Polym. J. 69 (2015) 284-295.

[44]. S. O. Han, J. H. Youk, K. D. Min, Y. O. Kang, W. H. Park, Electrospinning of cellulose acetate nanofibers using a mixed solvent of acetic acid/water: Effects of solvent composition on the fiber diameter, Materials Letters, 62 (2008) 759 - 762.

[45]. L. Li, Z. Jiang, M. Li, R. Li and T. Fang, Hierarchically structured PMMA fibers fabricated by electrospinning, RSC Adv., 4 (2014) 52973-5298. 
[46]. C. L. Casper, J. S. Stephens, N. G. Tassi, D. B. Chase, J. F. Rabolt, Controlling surface morphology of electrospun polystyrene fibers: Effect of humidity and molecular weight in the electrospinning process, Macromolecules 37 (2004) 573-578. 